\title{
Challenges of Measuring Residual Stresses in Large Girth Welded Pipe Spools by Neutron Diffraction
}

\author{
Yao Ren ${ }^{1, a^{*}}$, Anna Paradowska, b, Elvin Eren ${ }^{3, c}$, Bin Wang ${ }^{1, d}$ \\ ${ }^{1}$ Brunel University London, Kingston Lane, Uxbridge, Middlesex UB8 3PH, UK \\ ${ }^{2}$ ANSTO, Bragg Institute, Lucas Heights, NSW 2234, Australia \\ ${ }^{3}$ TWI Ltd, Granta Park, Great Abington, Cambridge, CB21 6AL, United Kingdom

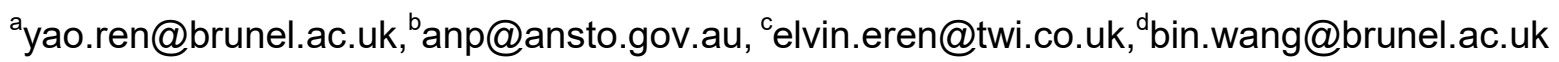

\section{Keywords: Residual Stress, Neutron Diffraction, Girth Welded Pipe}

\begin{abstract}
In this paper, welding induced residual stresses in a welded API 5L X65 girth pipe spools are discussed in as-welded and in local post weld heat treated conditions. Stress measurements were carried out non-destructively using the neutron diffraction technique. For such large-scale components residual stress measurements require significant preparation and planning. First of all, a choice of stress free lattice spacing value, discussed extensively, is of great importance for the evaluation of residual strains and stresses correctly. Besides, the use of a virtual instrument (SSCANSS software) can optimize measurements for distorted or undistorted large components with or without complex details. Moreover, the well-planned "window" cut through the thickness greatly reduced measurement time. A number of points were measured across the weld, HAZ and the parent material. Measurement results showed that residual stresses in the as-welded condition was lower than the yield strength of the material, and significant relaxation was also observed in the post weld heat treated samples.
\end{abstract}

\section{Introduction}

Welding residual stresses are generated due to the thermal cycle induced incompatible internal strain that remained in the weld structure after cooling. The nature of the residual stresses and the factors affecting the stress conditions are discussed in Leggatt's paper [1]. With regard to the integrity of welded structures, high tensile residual stresses existing in pipeline weldments reduce the load capacity, increasing proximity to brittle fracture together with the applied external loads.

There are various measurement methods available, either destructive or non-destructive for evaluating residual stress states of componment. The neutron diffraction technique has been widely used in numerous research work [2-7] for the measurement of welding residual stresses due to its advantages. Basically, all three components of the residual stress can be measured non-destructively. Besides, the intensity of the beam enables penetration into the bulk material and through thickness stress profiles can be obtained [7-10]. The principle of measuring residual stress using neutron diffraction is to determine residual strains directly by quantifying changes in lattice spacing from their stress-free condition [11-13].

In this study, relatively large girth welded pipe spools were investigated. The welding procedure (representative of a procedure used in the industry) was described in the authors' previous work [14]. In this paper, the focus is on the experimental challenges in neutron diffraction procedure used for residual stress measurements. The emphasis in the rest of this paper will be on the choice of a representative strain-free reference for neutron diffraction to measure residual stresses before and after post weld heat treatment (PWHT). 


\section{Residual stress measurements by neutron diffraction}

The principles of determining the residual stress magnitude are based on Bragg's Law and Hooke's Law. Equipped with Opal reactor neutron source at Australia Nuclear Science and technology Organization (ANSTO), Kowari strain scanning diffractometer utilizes the intense continuous monochromatic neutron beam to conduct strain scanning on samples.

The components investigated were made of API 5L X65 pipeline material. The dimensions of the girth welded pipe spool that used for stress evaluation by neutron diffraction were in $355.6 \mathrm{~mm}$ (14 inch) outside diameter, $19.1 \mathrm{~mm}$ wall thickness and $1000 \mathrm{~mm}$ length. A six-pass narrow-gap girth weld was located in the middle of the pipe spool. The welding and PWHT procedures were described in a previous publication [14]. At this point, it is worth noting that both furnace and local post weld heat treatment methods were employed in this study but the results concerning local PWHT are discussed in this paper.

For the evaluation of the welding residual stresses, three line-scans parallel to the axis of the pipe spool were carried out. They were located $3 \mathrm{~mm}$ below the pipe outer surface, $3 \mathrm{~mm}$ above the pipe inner surface and at the mid-thickness. Through thickness measurements were conducted at weld center and weld toes. A set of measurement points across the weld in parent metal, heat affected zone and weld material are show in Fig. 2a. A window cut was introduced for measuring the axial strain component (Fig. 2b) before embarking on the measurements in as-welded condition. This window greatly reduced path length travelled by the neutrons. For the measurement of the pipe spool in post heat treated condition, another window was introduced for hoop strain measurements (Fig. 2c and 2d). Following PWHT, residual strain components were measured at the same locations as in Fig. $2 \mathrm{a}$.

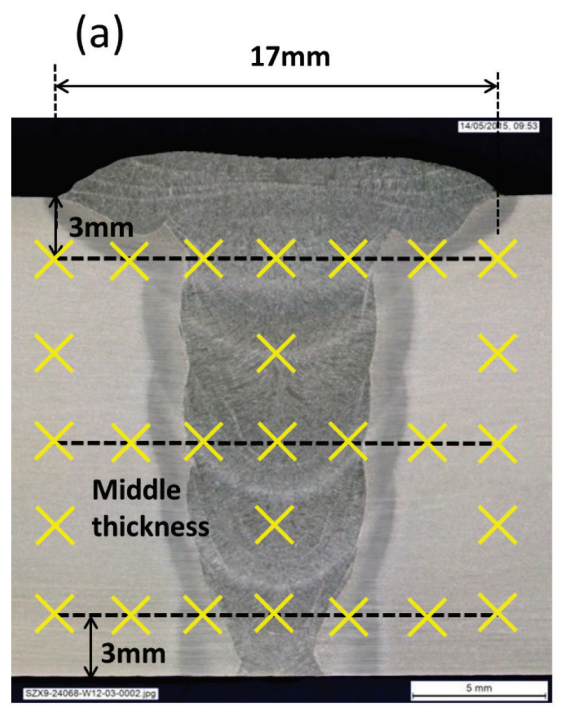

(b)
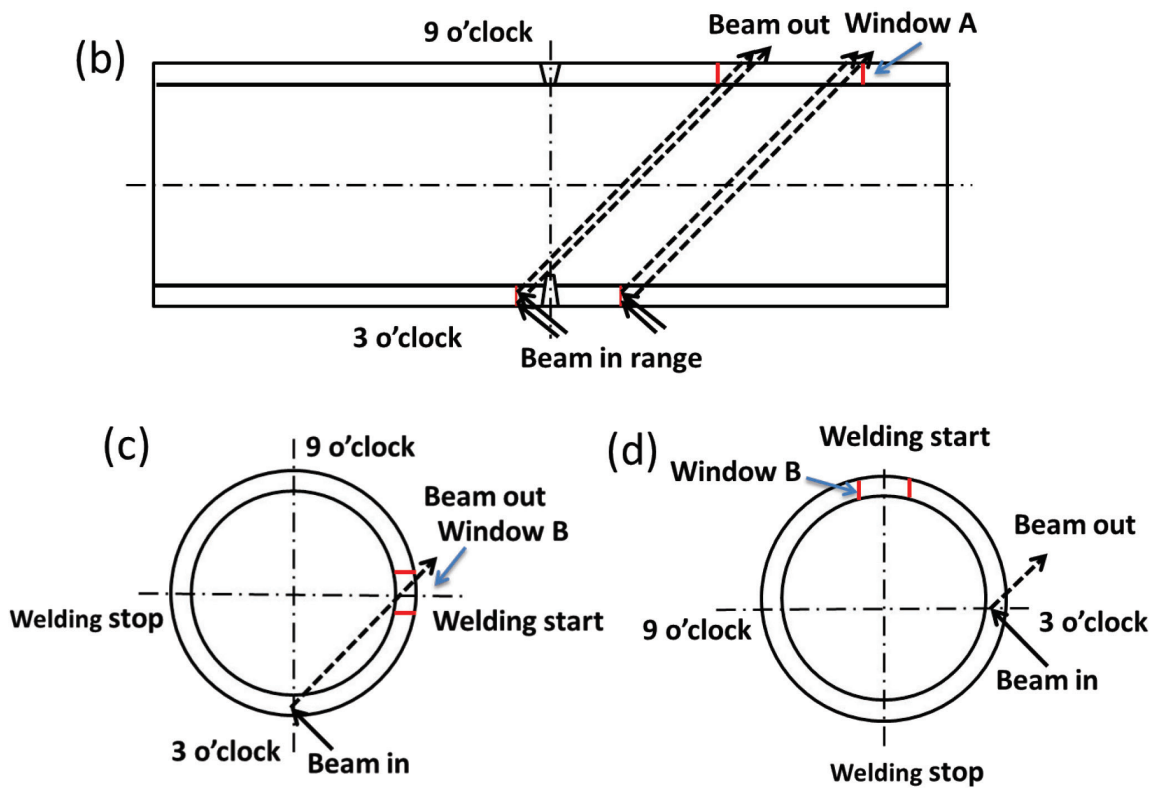

Fig. 2 Measurement locations and reduced travel path of neutrons after cutting a window on the pipe spool

Residual stress values were calculated using hkl specific material properties for the measured planes based on the Kröner model using the software DECcal [14]. The average reported errors range was $\pm 15 \mathrm{MPa}$. These errors are the peak fitting errors and do not take into account other possible sources of errors.

Stress-free comb sample ( $\mathrm{d}_{0}$ sample) was extracted from another pipe spool which was fabricated using the identical welding procedure. This sample was cut from the 3 o'clock position to make sure that the target micro-structure and geometry is replicated. The $\mathrm{d}_{0}$ comb sample was $6 \mathrm{~mm}$ thick and $95 \mathrm{~mm}$ long, containing the whole weld cross section and part of the parent material (Fig. 3). The strain component directions were defined the same as the corresponding orthogonal 
(axial, hoop and radial) directions in the pipe. The slits in through pipe thickness direction were cut by Electrical Discharge Machining (EDM) and repeated every $6 \mathrm{~mm}$ to create the 'teeth' on the sample. Additionally, two line-cuttings were introduced perpendicular to the "teeth" to manufacture $6 \times 6 \times 6 \mathrm{~mm}^{3}$ grids on the comb sample. These procedures enabled the welding induced residual stresses in the comb sample to relax in hoop, axial as well as radial directions, and are supposed to provide the sample in a strain-free condition.

There were 24 points measured on the stress-free sample. The numbers shown in the Fig. 3 demonstrate the scanning points sequence on the grids. With the given gauge volume $3 \times 3 \times 4 \mathrm{~mm}^{3}$, the measurements in three directions for each point were carried out focusing the beam at the center of each grid. At each scanning point, lattice spacing parameter $\mathrm{d}_{01}$ (supposed stress free lattice spacing in the as-welded condition) was measured in three orthogonal directions. The comb sample was subject to the same PWHT procedure as the pipe spool so that the same PWHT procedure is replicated on the comb. Lattice spacing parameters in it were measured again to obtain new lattice spacing $\mathrm{d}_{02}$ values (stress free spacing after PWHT) for the evaluation of the residual stress state.

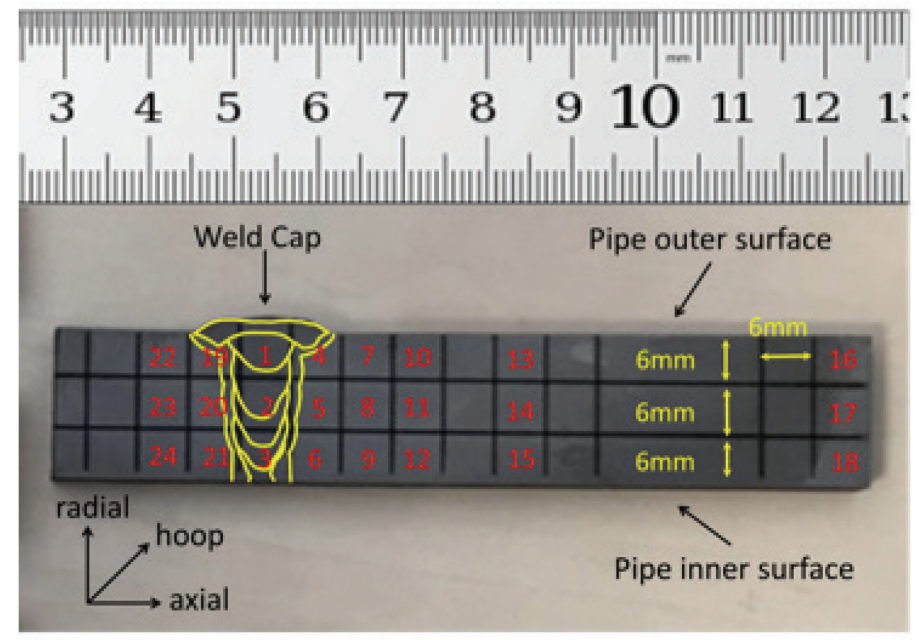

Fig. 3 The $d_{0}$ grid sample for calculating the strain-free inter-plane spacing

Assuming that hoop stress in the grid sample was completely relaxed during EDM cutting, 24 convoluted d-spacing values were calculated by using Hook's Law for each point. Averaging the values obtained from parent metal (from point 7 to point 18 and point 22 to 24 ), $\mathrm{d}_{01 \mathrm{p}}$ was calculated and selected as the strain-free d-spacing to calculate the relative strains in hoop, axial, normal directions as well as the convoluted strain variation in the parent material. These values provided the information regarding the strain variation hence the stress magnitude variation. After PWHT, all the data were analyzed following a similar procedure. An averaged strain-free d-spacing value was obtained from all the measurement locations in the parent material which was defined as $\mathrm{d}_{02 \mathrm{p}}$. Strain variation in the weld metal and parent metal was compared as well. In this work, the lattice spacing in HAZ was not able to be accurately measured. This is because the HAZ was only $1 \mathrm{~mm}$ wide in the narrow gap weld which was much smaller than the individual dimensions of the gauge volume.

Due to the large scale and complexity of the components to be measured, careful planning of the experiment was of great importance. KOWARI virtual instrument within Strain Scanning Simulation Software (SScanSS) [16] was adopted to plan and locate the measurement points accurately and maximize the efficiency of the experiment. The software was used in the planning and execution of measurement of the residual stress on both the pipe and the $\mathrm{d}_{0}$ sample. Prior to neutron diffraction scanning (Fig. 4 left), 3D models of the pipe and the $\mathrm{d}_{0}$ sample were created by laser scanning the surfaces. Measurement points were positioned on the sample models and the scanning sequence was displayed as the point number. Each scan was simulated to predict the measurement time and to check the orientation of the sample. 


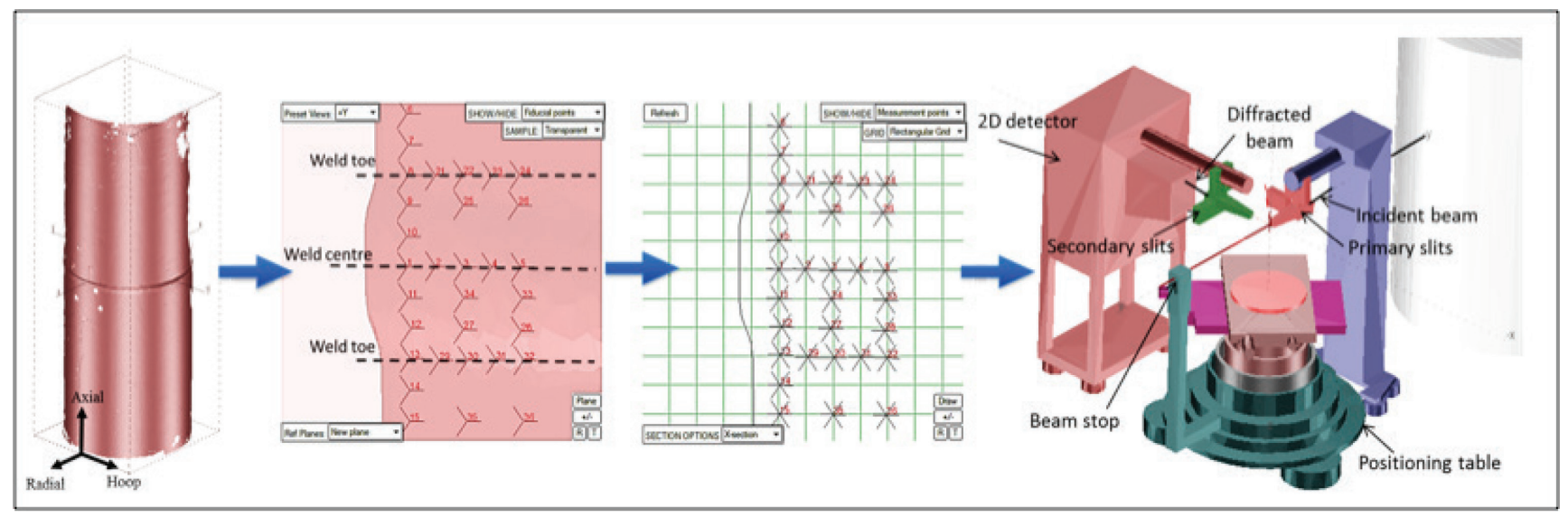

Fig. 4 The adoption of SScanSS software to pre-design the measurement points on the laser scanned $3 D$ pipe model

\section{Results and discussion}

\section{Reference (comb) sample}

Strain values in the reference sample in as-welded condition were calculated using the $\mathrm{d}_{01 \mathrm{p}}$ values shown in Fig. 5a. The values following PWHT (Fig. 5b) were calculated using $\mathrm{d}_{02 \mathrm{p}}$. These strain distributions illustrate the strain variation in the $\mathrm{d}_{0}$ sample. In Fig. $5 \mathrm{a}$ and $5 \mathrm{~b}$, it also emphasizes the importance of selecting position dependent (weld metal, heat affected zone and parent metal) $d_{0}$ values for calculating the residual stresses.
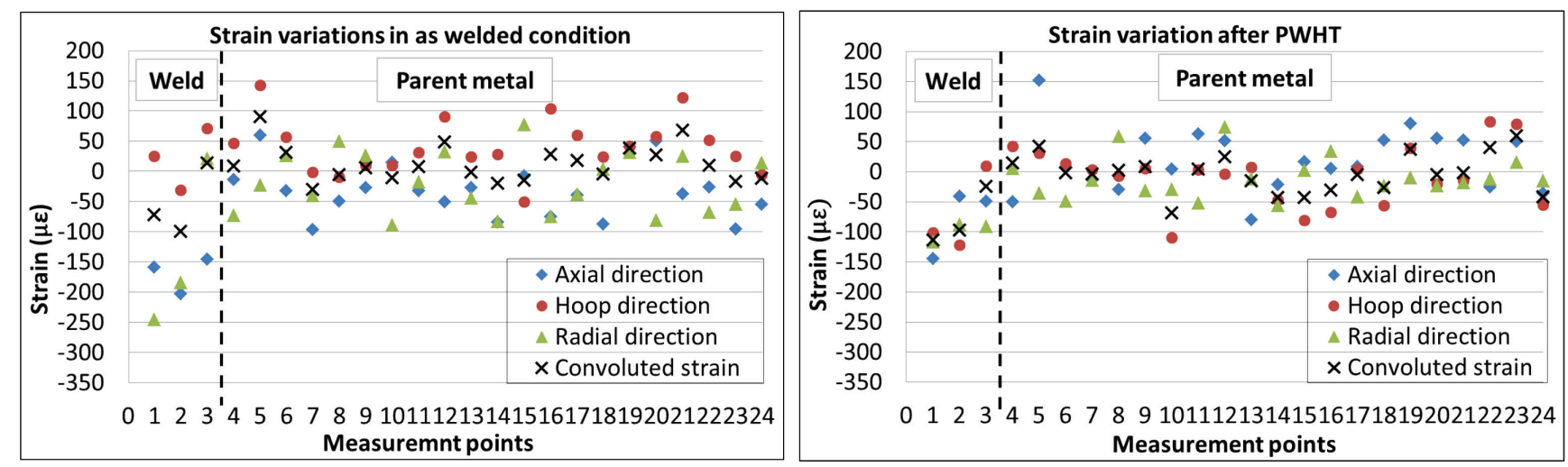

Figure 5. Strain variation based on selected reference d-scpacing values

In the as-welded condition, the averaged $\mathrm{d}_{0}$ value, designated as $\mathrm{d}_{01 \mathrm{p}}$, was selected to calculate strains in the parent material. There was approximately less than $100 \mu \varepsilon$ variation and this leads to approximately $20 \mathrm{MPa}$ stress deviation in any single direction. However, in the weld metal, higher strain variations exceeding $200 \mu \varepsilon$ occurred in axial and radial components resulting in up to $50 \mathrm{MPa}$ stress error. Therefore, position dependent $d_{0}$ values obtained from the weld of the stress free sample should be used to evaluate the stresses in the weld metal of the pipe in the as-welded condition.

In the PWHT condition, the use of averaged $\mathrm{d}_{0}$ value, designated as $\mathrm{d}_{02 \mathrm{p}}$, exhibited smaller strain variation in all directions as well as the convoluted strain. This d-spacing valued was used for the calculation of the stresses in the parent material after PWHT. The variation in the strain in the weld metal was less than $100 \mu \varepsilon$. However, it is also worth noting that the stresses remaining in the component following PWHT were significantly smaller. Therefore, for the evaluation of the stress state in the weld region, an averaged convoluted $\mathrm{d}_{0}$ value obtained from weld metal measurements (measurement points 1,2 and 3) was used, see Fig. 6. 

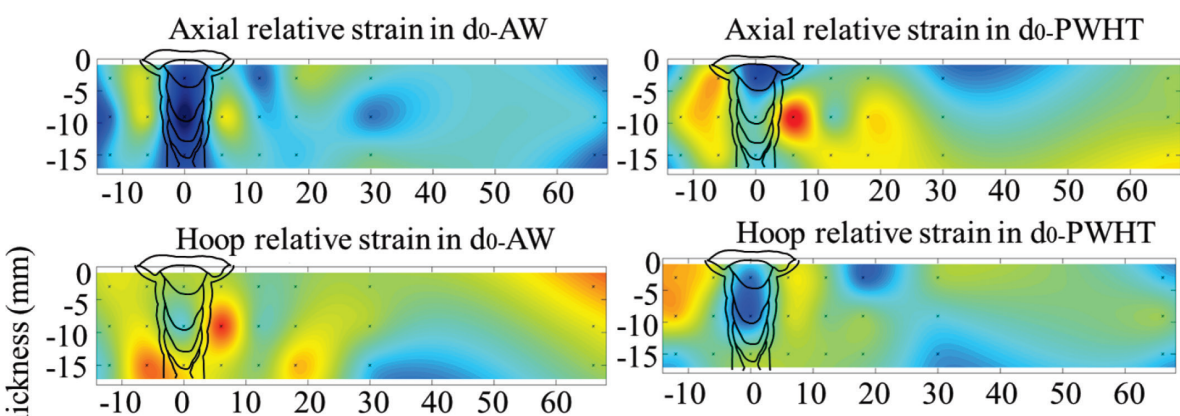

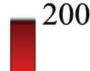

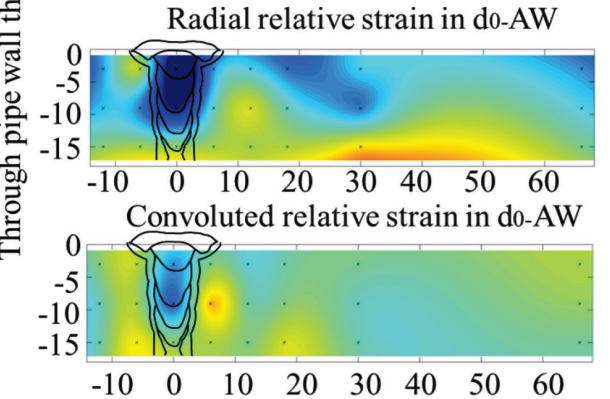

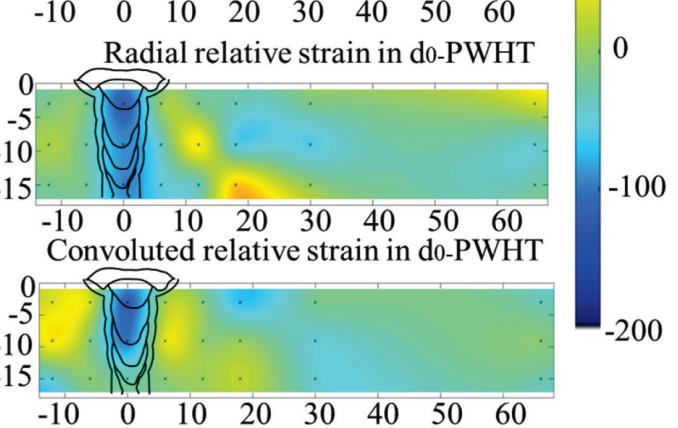

Along pipe length direction(mm)

Fig. 6 Normalized strain variation maps of the comb sample before (left) and after (after) PWHT

\section{Residual stress states before and after PWHT}

Residual stress profiles in through thickness direction in the as-welded and post weld heat treated conditions are shown in Fig.7. Hoop stresses were normalized with respect to the greater $\left(\sigma_{\mathrm{y}}^{+}\right)$of the weld and parent material, and axial stresses were normalized with respect to the lower value $\left(\sigma_{\mathrm{y}}^{*}\right)$ of the two [15] using the $0.2 \%$ proof strength of the parent material and weld metal. The weld was overmatching. Yield strength of weld metal $\left(\sigma_{\mathrm{y}}^{+}\right)$was $657 \mathrm{MPa}$ and this value was used for normalizing the hoop stresses. For normalizing the axial stresses, parent material yield stress $\left(\sigma_{\mathrm{y}}^{*}\right)$ $510 \mathrm{MPa}$ of was used.

Through thickness residual stress profiles at weld center and toe were presented in Fig.7. Compared to the uniform, yield magnitude profile advised in BS7910 for the as-welded condition, much lower residual stress values were obtained from the measurements in the as-welded condition. Following PWHT, it was seen that axial stresses reduced to less than the $20 \%$ of yield strength of the parent material at room temperature. Hoop stresses were significantly lower than $30 \%$ of the yield strength of the weld metal at room temperature.

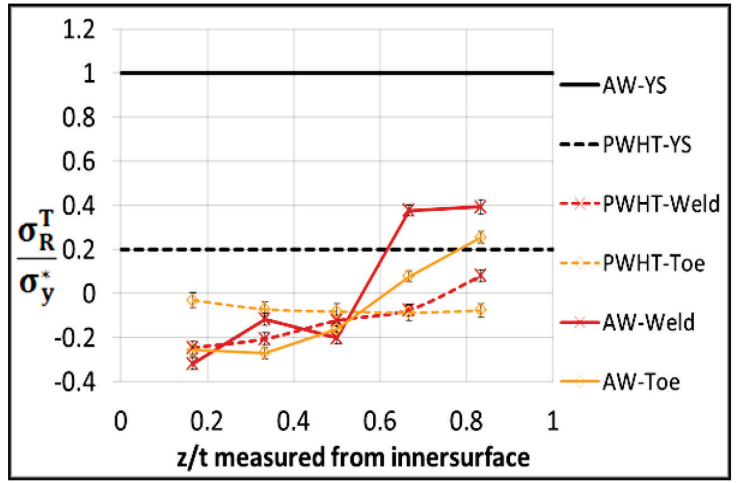

(a) Axial stresses

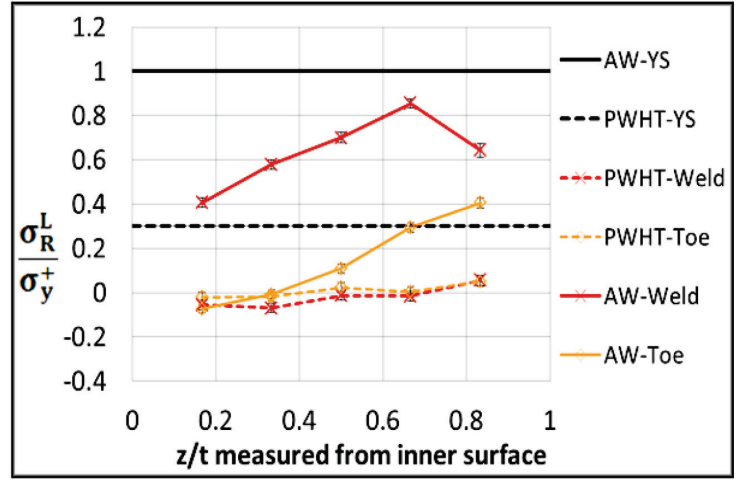

(b) Hoop stresses

Figure 7. Normolised througth thickness residual stresses at weld center and toe before and after PWHT 


\section{Conclusions}

1. Utilizing the virtual model to determine the neutron diffraction measurement points in such a large pipe spool improved the measurement location accuracy and enabled simulation of the scanning process as well as prediction of time required for each scan in advance. Cutting windows on the pipe greatly reduced measurement time.

2. The evaluation of the strain-free lattice spacing was essential to the subsequent residual stress calculation. Selecting appropriate d-spacing values for corresponding weld metal, heat affected zone and parent metal eliminated the strain variation resulting from chemical composition.

3. Residual stresses after local PWHT reduced in both axial and hoop directions in girth welded pipe spool. The results proved that the residual stress profile advised in BS7910 for furnace PWHT condition was conservative for the case presented in this paper.

\section{References}

[1] R. H. Leggatt, "Residual stresses in welded structures," Int. J. Press. Vessel. Pip., vol. 85, no. 3, pp. 144 151, Mar. 2008. http://dx.doi.org/10.1016/j.ijpvp.2007.10.004

[2] T. Lorentzen, "Nondestructive evaluation of residual stresses by neutron diffraction," NDT Int., vol. 21, no. 6, pp. 385-388, Dec. 1988. http://dx.doi.org/10.1016/0963-8695(88)90160-0

[3] G. Albertini, G. Bruno, P. Calbucci, F. Fiori, M. Rogante, and F. Rustichelli, "Non-destructive determination of residual stresses in welded components using neutron diffraction," Weld. Int., vol. 12, no. 9, pp. 698-703, Jan. 1998. http://dx.doi.org/10.1080/09507119809452037

[4] M. J. Park, H. N. Yang, D. Y. Jang, J. S. Kim, and T. E. Jin, "Residual stress measurement on welded specimen by neutron diffraction," J. Mater. Process. Technol., vol. 155-156, pp. 1171-1177, Nov. 2004. http://dx.doi.org/10.1016/j.jmatprotec.2004.04.393

[5] A. Paradowska, J. W. H. Price, R. Ibrahim, T. R. Finlayson, R. Blevins, and M. Ripley, "Residual stress measurements by neutron diffraction in multi-bead welding," Phys. B Condens. Matter, vol. 385-386, pp. 890-893, Nov. 2006.

[6] Y. V Taran, a M. Balagurov, J. Schreiber, and U. Stuhr, "Residual stresses in a shape welded steel tube by neutron diffraction," J. Phys. Condens. Matter, vol. 20, no. 10, p. 104258, Mar. 2008. http://dx.doi.org/10.1088/0953-8984/20/10/104258

[7] T. Neeraj, T. Gnäupel-Herold, H. J. Prask, and R. Ayer, "Residual stresses in girth welds of carbon steel pipes: neutron diffraction analysis," Sci. Technol. Weld. Join., vol. 16, no. 3, pp. 249-253, Apr. 2011. http://dx.doi.org/10.1179/1362171810Y.0000000028

[8] S. V. Pearce and V. M. Linton, "Neutron diffraction measurement of residual stress in high strength, highly restrained, thick section steel welds," Phys. B Condens. Matter, vol. 385-386, pp. 590-593, Nov. 2006.

[9] W. Woo, V. Em, P. Mikula, G.-B. An, and B.-S. Seong, "Neutron diffraction measurements of residual stresses in a 50mm thick weld," Mater. Sci. Eng. A, vol. 528, no. 12, pp. 4120-4124, May 2011. http://dx.doi.org/10.1016/j.msea.2011.02.009

[10] W. Woo, V. T. Em, B. S. Seong, P. Mikula, and G. B. An, "Residual stress determination in a thick ferritic steel weld plate using neutron diffraction," J. Mater. Sci., vol. 47, no. 14, pp. 5617-5623, Apr. 2012. http://dx.doi.org/10.1007/s10853-012-6456-5

[11] G. E. Bacon, Neutron diffraction, 3rd ed. United Kingdom: Clarendon Press., 1975.

[12] P. J. Withers, M. Preuss, A. Steuwer, and J. W. L. Pang, "Research papers methods for obtaining the strainfree lattice parameter when using diffraction to determine residual stress research papers," pp. 891-904, 2008.

[13] Paradowska, A., Finlayson, T., Price, J.W.H., Steuwer A., Ibrahim, R., Ripley, M., Investigation of Reference Samples for Residual Strain Measurements in a Welded Specimen by Neutron and Synchrotron X-ray Diffraction, Physica B: Condensed Matter, 2006, 385-389:890-893. http://dx.doi.org/10.1016/j.physb.2006.05.241

[14] Y. Ren, A. Paradowska, B. Wang, and E. Eren, "PVP2016-63378," in Proceedings of the ASME 2016 Pressure Vessels and Piping Conference, 2016, pp. 1-9.

[15] J.A. James, L. Edwards, Application of robot kinematics methods to the simulation and control of neutron beam line positioning systems. Nuclear Instruments and Methods in Physics Research A., 2007, 571: 709-718.T. Manns; B. Scholtes, "DECcalc - A Program for the Calculation of Diffraction Elastic Constants from Single Crystal Coefficients," Mater. Sci. Forum, vol. 681, no. 2, pp. 417-419. http://dx.doi.org/10.1016/j.nima.2006.11.033

[16] BSI, "BS7910:2013 Guide to methods for assessing the acceptability of flaws in metallic structures," 2013. 